Supporting information for

\title{
Conformational selectivity of peptides for single-walled carbon
} nanotubes

\author{
Zhengding Su, Tong Leung \& John F Honek, \\ Department of Chemistry, University of Waterloo, Waterloo, ON N2L 3G1, Canada
}




\section{Materials and methods}

Phage-peptide libraries and phage construction

Three M13 phage-peptide libraries were subjected to biopanning for SWNT binding peptides and they were Ph.D-12, Ph.D-C7C and Ph.D-7 libraries, which were purchased from NEB (Beverly, MA). These libraries are based on M13 phage and contain either linear 12 or 7 random peptide sequences (i.e. Ph.D-12, and Ph.D-7 libraries) or constrained 7 residue random peptide sequences (i.e. Ph.D-C7C library). The complexity of these libraries was at least $10^{9}$, and their titer was $10^{12} \mathrm{pfu} / \mathrm{ml}$.

Three published phage sequences containing B3, B4 and $\phi \mathrm{NH}-12-5-2$ peptides 1;2 with high-affinity to either multi-walled carbon nanotubes (MWNTs) or singlewalled carbon nanohorns (SWNHs) were reconstructed within a M13KE vector. For the gene encoding each peptide including the pIII leader sequence, two primers were used to generate dsDNA fragments with two restriction sites (i.e. Kpn I and Eag I) in the 5'or 3'- ends, respectively. PCR reactions were performed in standard protocols with Taq DNA polymerase (Roche Diagnostics, Laval, QC). The PCR products were directly used for sequential digestions. After each digestion, the reaction was purified using a Qiagen PCR purification kit (Mississauga, ON). Individual inserts were ligated overnight with pre-digested M13KE vector at $16{ }^{\circ} \mathrm{C}$. The transformation was performed by standard protocols with ER2738 competent cells, prepared utilizing the methods of Inoue et al ${ }^{3}$. The transformed cells were titrated and DNA sequences were screened by PCR and confirmed by DNA sequencing. 


\section{Biopanning and sequencing}

Short single-walled carbon nanotubes (SWNTs) were purchased from SigmaAldrich (Cat \# 652512, Lot \# 09310HD, Oakville, ON). This is currently a commercially available source of very high purity SWNTs, which were made by chemical vapor deposition (CVD). A detailed screening procedure using phage peptide libraries is summarized in Scheme S1. Initially, SWNTs $(1 \mathrm{mg} / \mathrm{ml})$ were suspended by sonication using a Branson Sonifier 200 sonicator (Danbury, CT) equipped with a 4 mm diameter micro tip in TBS buffer (50 mM Tris-HCl, $150 \mathrm{mM} \mathrm{NaCl,} \mathrm{pH} \mathrm{7.5)}$ containing $0.1 \%$ Tween-20. The tip was placed into the sample approximately one-third of the distance from the surface and sonicated for 30 min with multiple 30 second bursts followed by intervals of 50 seconds for cooling at a power level of $13 \mathrm{~W}$. To minimize the isolation of graphite selective phage, $10 \mu \mathrm{l}$ of each phage library was preincubated with a graphite (Alfa Aesar, Ward Hill, MA, Cat \#: 14734, Lot \#: D02P23) suspension ( $1 \mathrm{mg} / \mathrm{ml}$ in TBS, 0.1\% Tween-20 and $2 \%$ BSA) prepared by sonication. The mixture was gently agitated at room temperature for $60 \mathrm{~min}$. The unbound phage were recovered by centrifugation at $10,000 \mathrm{x}$ g for $10 \mathrm{~min}$ and the supernatant directly used for panning against SWNTs. Panning experiments were initiated by mixing $200 \mu \mathrm{l}$ of the recovered phage with $200 \mu \mathrm{l}$ of the SWNT suspension. The samples were incubated at room temperature for at least $60 \mathrm{~min}$ with gentle agitation. Unbound phage were removed by washing 5 times with $1 \mathrm{ml}$ TBS buffer containing the same concentration of Tween-20. Bound phage were eluted by incubating the particles with 1 $\mathrm{ml}$ of $1 \mathrm{mg} / \mathrm{ml} \mathrm{BSA}$ in $2 \mathrm{M}$ glycine- $\mathrm{HCl}(\mathrm{pH} 2.2)$ for less than $10 \mathrm{~min}$. The eluted phage 
was immediately neutralized by adding $150 \mu \mathrm{l}$ of $1 \mathrm{M}$ Tris- $\mathrm{HCl}(\mathrm{pH}$ 9.1) and the phage concentration was scored by titration using E. coli strain ER2738. The eluted phage were amplified and subjected to the next round of biopanning. Biopanning was repeated 6 times with increasing Tween-20 concentrations (i.e. $0.2 \%, 0.3 \%, 0.4 \%, 0.5 \%$, 0.75 and $1.0 \%$ ). Phage particles randomly selected from the last three panning steps were characterized by DNA sequencing with the universal primer 96 gIII (NEB). 


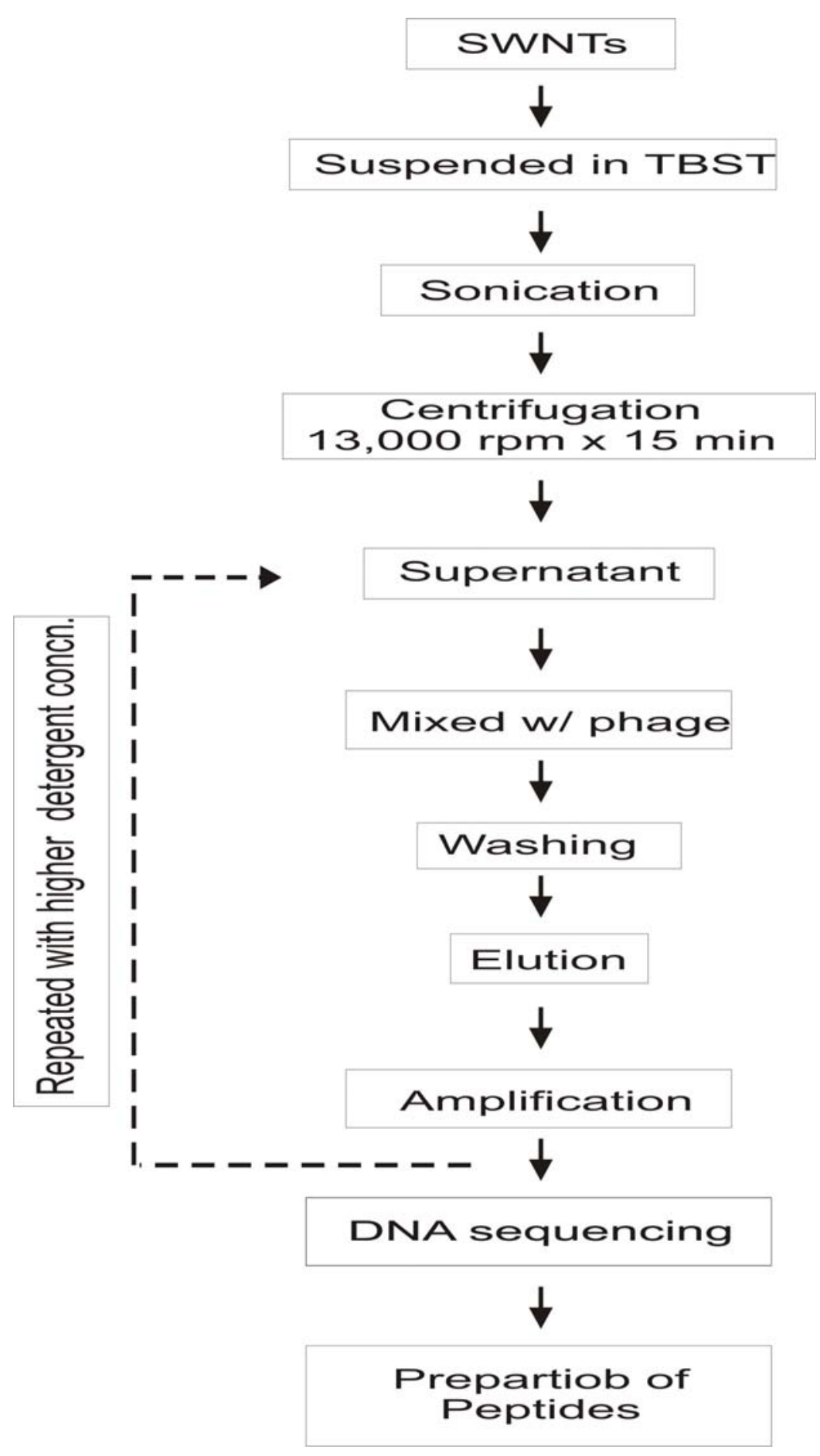

Scheme S1. Summary of biopanning procedure of screening SWNT-binding peptides. 


\section{Binding assay}

Binding affinity of selected peptides to SWNTs was quantitated by two different methods. (1). The binding affinity was measured in whole phage particles and defined by the number of plaque-forming units in the binding pool ${ }^{2}$. To compare binding affinity among different phage, $\sim 10^{11}$ pfu of phage (input) in $200 \mu \mathrm{l}$ of TBS containing $2 \%$ BSA, $0.1 \%$ Tween-20, were mixed with $250 \mu \mathrm{l}$ of $1 \mathrm{mg} / \mathrm{ml}$ SWNTs and incubated at room temperature for $60 \mathrm{~min}$. Particles were then washed 5 times with 1 $\mathrm{ml}$ of the same buffer except that the concentration of Tween-20 was $0.3 \%$. The bound phage were eluted with acid and assessed by titration (output). The binding specificity was defined as the ratio of output/input phages ${ }^{1}$. (2). The binding affinity was also determined by measuring the amount of protein (or peptide) binding to SWNTs. In the current work, a fusion protein in the form of MFH-Pep (see Figure S1) was directly used. The control experiment was done with MFH (Figure S1) to exclude possible nonspecific binding. The fusion protein was incubated with SWNTs and washed with TBS buffer containing $0.1 \sim 0.3 \%$ Tween-20 till the $\mathrm{OD}_{280 \mathrm{~nm}}$ in the washing solution did not decrease. Bound proteins were eluted with the acid elution buffer (see above) and the concentration of the proteins was spectroscopically determined with coefficient constants calculated by the method of Gill et al ${ }^{4}$. To determine the SWNT concentration, a standard curve was prepared by measuring bound BSA proteins versus defined SWNT amounts (e.g. Figure S2) and the SWNT concentration in each sample was calibrated with the standard curve. BSA concentration was calculated with a 
coefficient constant of $\varepsilon_{280 \mathrm{~nm}}=43800 \mathrm{M}^{-1} \mathrm{~cm}^{-1}$ obtained using a Bradford assay kit (BIO-RAD, Hercules, CA).

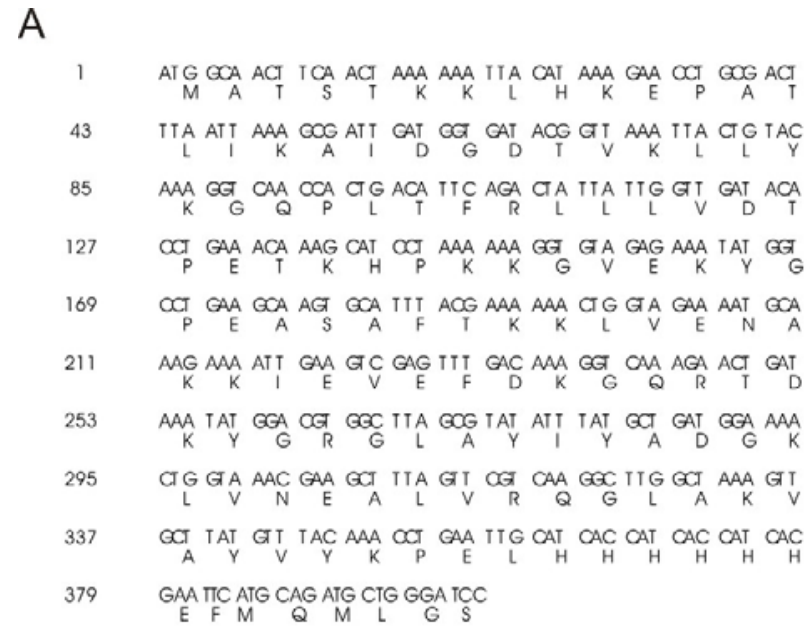

B

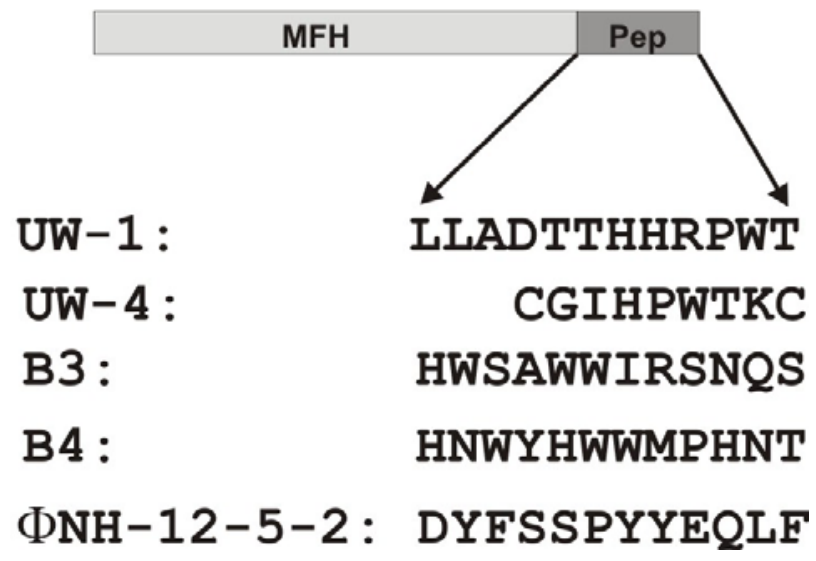

Figure S1. The structure of fusion proteins used in this study. A. DNA sequence of MFH with encoded amino acids used in the fusion protein expression vector, pMFHMCS ${ }^{5}$. The DNA fragments encoding peptides listed in panel $B$ were inserted between EcoR I and BamH I sites. B: A schematic representation of fusion protein used in the study. MFH: fusion carrier; Pep: CNT-binding peptides. The amino acid sequences of five peptides in this study are also listed. 


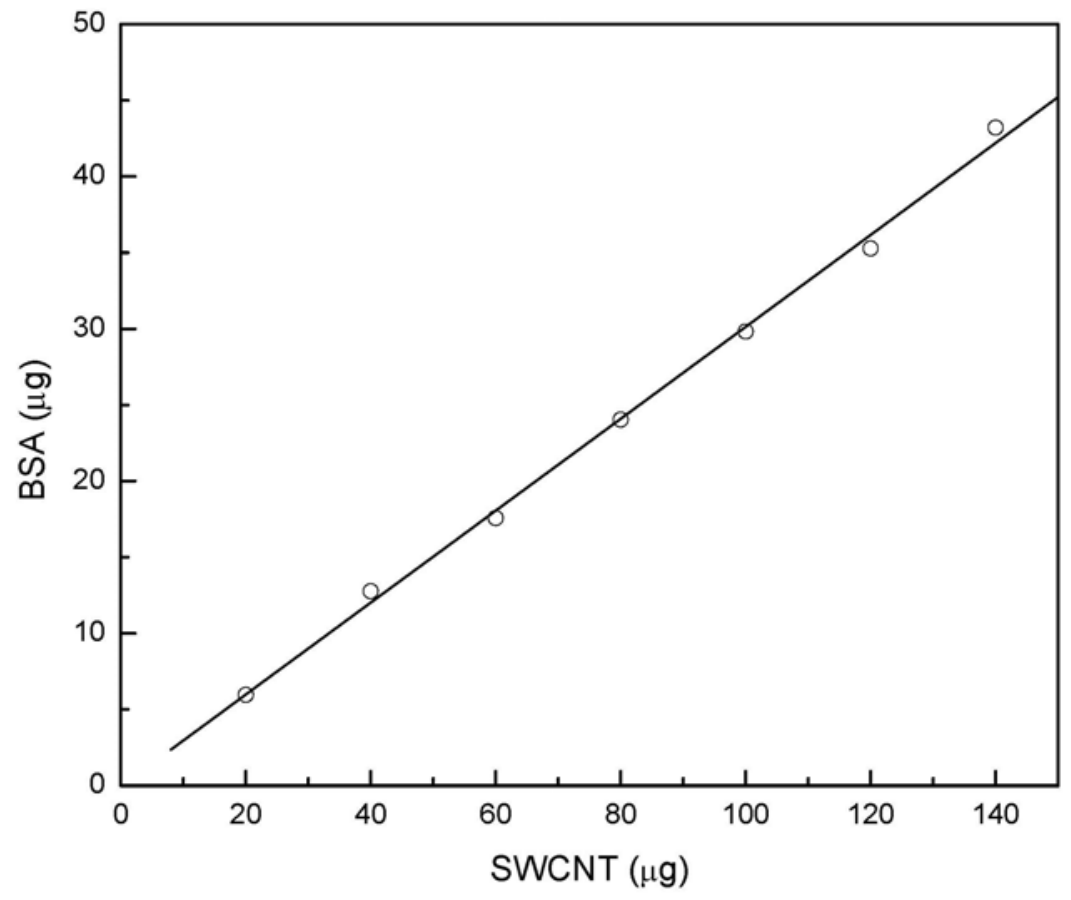

Figure S2. A standard assay curve that was utilized to determine the concentration of SWNTs.

\section{Preparation of peptides}

All the peptides were prepared with a recombinant DNA approach described previously ${ }^{5}$ except where otherwise indicated. A methionine-free carrier protein termed MFH (see Figure S1), a variant of the SFC120 fusion carrier ${ }^{6}$, was used to fuse with the targeted peptide. In this study, the multiple cloning sites (MCS) were re-engineered to be able to clone tandem inserts via an $A l w N I$ restriction site (see Figure S1). Synthetic peptides were purchased from the Peptides Facility of the Biotechnology Research Institute (Montreal, QC). 
Fusion proteins were prepared by transforming the particular plasmids into the E coli BL21(DE3) host strain. An overnight culture $(50 \mathrm{ml})$ grown in LB containing ampicillin $(100 \mu \mathrm{g} / \mathrm{ml})$ was used to inoculate $1 \mathrm{~L}$ of LB medium supplemented with ampicillin $(100 \mu \mathrm{g} / \mathrm{ml}) .{ }^{15} \mathrm{~N}$-labeled peptides were expressed in M9 medium using $\left({ }^{15} \mathrm{NH}_{4}\right)_{2} \mathrm{SO}_{4}(1 \mathrm{~g} / \mathrm{L})$ as the sole nitrogen source. The cells were grown at $37{ }^{\circ} \mathrm{C}$ to a density of $\mathrm{OD}_{600 \mathrm{~nm}}=0.8$ and induced by adding IPTG to a final concentration of $1 \mathrm{mM}$. The induced cells were incubated for 12 hrs at $37^{\circ} \mathrm{C}$ and collected by centrifugation (8,000 rpm for $20 \mathrm{~min}$ ). The cell pellet was frozen at $-20^{\circ} \mathrm{C}$ before further processing.

Thawed cell pellets were resuspended in a lysis buffer containing $6 \mathrm{M}$ urea, 50 $\mathrm{mM}$ phosphate (pH 8.0), $100 \mathrm{mM} \mathrm{NaCl}$ by gentle shaking for 20 min and then sonicated for one minute on ice. The lysis mixture was then centrifuged at 10,000 rpm for 30 min and the supernatant was subjected to purification by Ni-nitrilotriacetic acid (Ni-NTA) affinity chromatography under denaturing conditions. Simply, the supernatant of the cell lysate was loaded onto a column equilibrated with the lysis buffer. The column was extensively washed with the lysis buffer containing $50 \mathrm{mM}$ imidazole, and this was followed by elution of the fusion proteins utilizing the lysis buffer containing $250 \mathrm{mM}$ imidazole. The eluent was desalted using a Waters Sep-Pak C18 column (Mississauga, ON) and the protein solution was lyophilized to dryness.

Cyanogen bromide $(\mathrm{CNBr})$ cleavage was used to release the target peptides from the fusion proteins. The fusion proteins were dissolved in $0.1 \mathrm{M} \mathrm{HCl}$ and $6 \mathrm{M}$ guanidine hydrochloride (at $10 \mathrm{mg}$ protein/ml). Crystalline CNBr (Sigma-Aldrich) was added to a final molar ratio of 100:1 of the fusion protein. The solution was allowed to stand for 12-24 hrs at room temperature. After the solution was neutralized with $\mathrm{NaOH}$ 
(1 M), the samples were then purified by utilizing Ni-NTA agarose beads to remove the MFH fusion carrier and undigested fusion protein. The flow-through was acidified and desalted using a Waters Sep-Pak C18 column and lyophilized.

Both the recombinant and synthetic peptides were finally purified using HPLC on a $\mathrm{C}_{18}$ reversed-phase column with a water-acetonitrile gradient with added $0.1 \%$ trifluoroacetic acid. The identities of all purified peptides were verified by a WatersMicromass Q-TOF Ultima Global LC/MS/MS system. Peptide concentrations were determined by comparing the $\mathrm{OD}_{280 \mathrm{~nm}}$ values of peptide stock solutions with the predicted extinction coefficient for each peptide ${ }^{4}$.

\section{Spectroscopic measurements}

Circular dichroism (CD) was performed on free peptides in solution or in the presence of SWNTs using a Jasco J-715 spectropolarimeter (Easton, MD). Peptides were dissolved in TBS buffer (pH7.5) at a concentration of $6 \sim 20 \mu \mathrm{M}$. The spectra were measured between 195 and $270 \mathrm{~nm}$ as the average of ten successive scans with a bandwidth of $1.0 \mathrm{~nm}$ and a scan speed of $20 \mathrm{~nm} / \mathrm{min}$. Steady-state tryptophan fluorescence measurements were made with a PTI QuantaMaster ${ }^{\mathrm{TM}}$ Model QM-4/2005 (Birmingham, NJ). Samples were dissolved in TBS buffer (pH 7.5) at a concentration of $2 \sim 10 \mu \mathrm{M}$. Excitation was set at $289 \mathrm{~nm}$, the emission fluorescence spectra were measured between 300 and $550 \mathrm{~nm}$ with a scanning speed of $150 \mathrm{~nm} / \mathrm{s}$ and an excitation slit of $1.0 \mathrm{~nm}$. 
Fluorescence resonance energy transfer (FRET)

The FRET efficiency was measured by the energy transfer efficiency

$$
E_{\text {FRET }}=\left(1-D_{A} / D\right)\left(1 / f_{A}\right)
$$

where $D_{\mathrm{A}}$ is the fluorescence intensity of the donor (Trp) in the presence of the acceptor and $D$ is the fluorescence intensity of the donor in the absence of the acceptor (i.e. Pro-Q Sapphire 365, Molecular Probes, Eugene, OR). The apparent efficiencies were normalized by $f_{\mathrm{A}}$ (the fractional labeling with acceptor) and in the current experiment it is mandatory to use a slight excess amount of the dye to ensure $f_{\mathrm{A}}=1$. The distance $R$ between the donor and acceptor was calculated by the Förster equation

$$
E_{\text {FRET }}=\left[1+\left(R / R_{0}\right)^{6}\right]^{-1}
$$

where the Förster radius $R_{0}$ is $27.5 \AA$ for the Trp-Sapphire 365 pair obtained through experimental determination of $E_{F R E T}$ for a standard protein with a known distance measured from its X-ray crystallographic structure (see Part III. Results and discussion).

\section{NMR experiments}

NMR spectra were acquired with a Bruker $600 \mathrm{MHz}$ NMR spectrometer at $25^{\circ} \mathrm{C}$ using standard pulse sequences ${ }^{7}$. The NMR samples were prepared by dissolving the peptides in TBS ( $\mathrm{pH}$ 7.5). Heteronuclear NMR experiments including heteronuclear single quantum coherence (HSQC) (2D), HSQC-nuclear Overhauser effects spectroscopy (NOESY) (3D) and HSQC-total correlation spectroscopy (TOCSY) (3D) were carried out for sequential assignments. Spectral processing, display and analysis 
were performed using the XwinNMR software package supplied with the spectrometer system. Sequence-specific assignment of the peptide HSQC spectrum was carried out with the NMRview Java software program ${ }^{8}$.

\section{Molecular Modeling}

Energy minimization was performed using the Discover_3 module in Accelrys Insight II software (Version 2005, San Diago, CA). An AMBER force field, Amber 99, was adopted, which was converted by the AmberFFC program ${ }^{9}$. The coordinates of SWNCT presented in PDB format were generated with the Accelrys MS Studio program (San Diego, CA). Peptide sequences were generated using the Biopolymer module in Accelrys Insight II.

\section{Results and Discussion}

\section{Selection of SWNT-binding phage}

The SWNT samples $(1 \mathrm{mg} / \mathrm{ml})$ were pre-treated with sonication (see Materials and methods) in TBS buffer containing $0.1 \%$ Tween-20. The mixtures stood overnight at ambient temperature to settle aggregates down as sediments, as the aggregates have irregular cavities on their surfaces observed by scanning electron microscopy (SEM) (data not shown) and they may cause non-specific binding. Thus, only the suspension was used for phage-display peptide screening. 
To minimize false results from the possible contamination of graphites in SWNT samples, each phage library was pre-incubated with a graphite suspension prepared by sonication (see Materials and methods). Subsequently, the "graphite-free binding” random peptide phage display library was incubated with SWNTs followed by washing away the unbound phage and eluting the specifically bound phage. These selected phage were then amplified and taken through additional binding /elution /amplification cycles with increasingly stringent conditions (i.e. Tween-20, see Materials and Methods) to enrich the pool in favor of the tightest binding sequences. The enrichment rate of the recovered phages approaches $80 \%$ after five panning rounds, i.e at $0.5 \%$ Tween-20 (Figure S3), and $10 \sim 30$ individual phages from the panning rounds at the higher concentration of Tween-20 (i.e. $0.5 \%, 0.75 \%$ and $1.0 \%$ ) were chosen among those identified as positive clones able to bind to SWNTs. The peptide sequences of these clones were deduced from their DNA sequences and summarized in Table 1. Note that sequencing results from screening a linear 7-mer peptide library are not shown in Table $\mathbf{1}$ as no conclusive consensus sequence was found. 


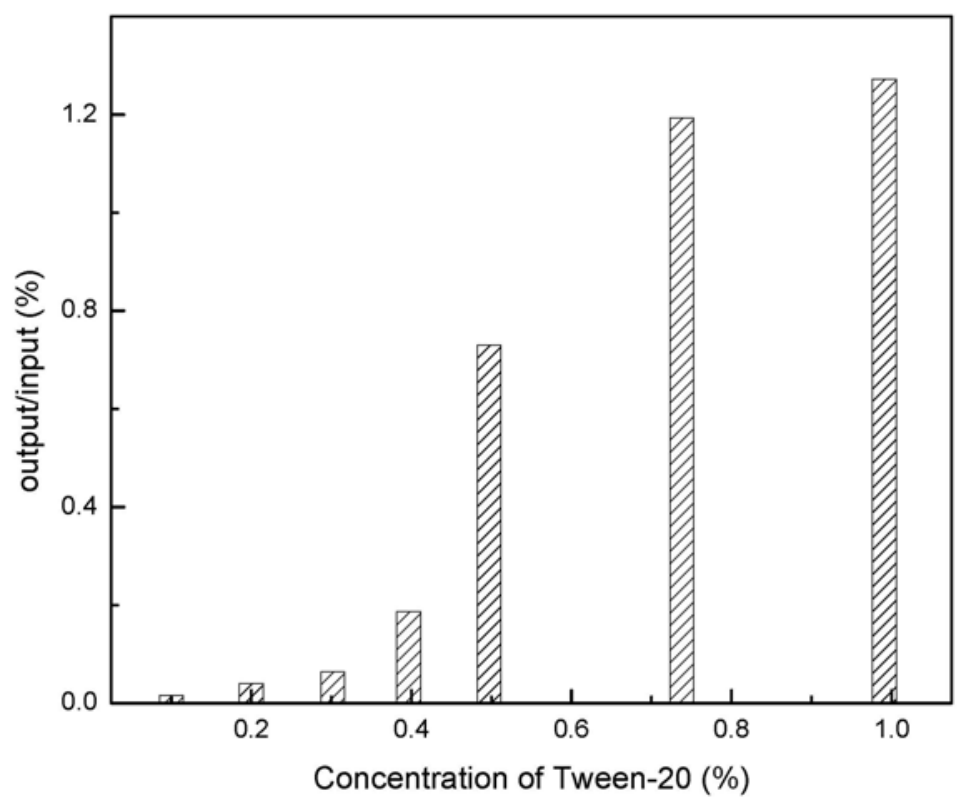

Figure S3. The ratio of output / input as a function of Tween-20 concentration.

Conformational characterization of SWNT-binding peptides by fluorescence spectroscopy

The interaction of the two SWNT binding peptides (i.e. UW-1 and B3) with SWNTs was also studied by steady-state fluorescence of the Trp residues. In the absence of SWNTs, the Trp maximum emission wavelength was at $350 \mathrm{~nm}$ for both UW-1 and B3 peptides, indicating a full exposure of the Trp indole ring to an aqueous environment (Figure S4). When UW-1 peptide binds to SWNTs, the maximum wavelength of the Trp emission shifts to approximate $343 \mathrm{~nm}$, suggesting that the Trp side chain was partially buried and was in a solvent inaccessible hydrophobic environment ${ }^{10}$. On the other hand, binding the current SWNTs to B3 peptide did not cause the maximum emission wavelength to shift (Figure S4B). This observation is consistent with the binding assays with the current SWNTs (see Table 2). It is likely 
that the existence of a compact conformation for B3 peptide ${ }^{2}$ may reduce its binding affinity to the current SWNT, compared to UW-1 peptide which has a relatively flexible conformation around the Trp residue.

A

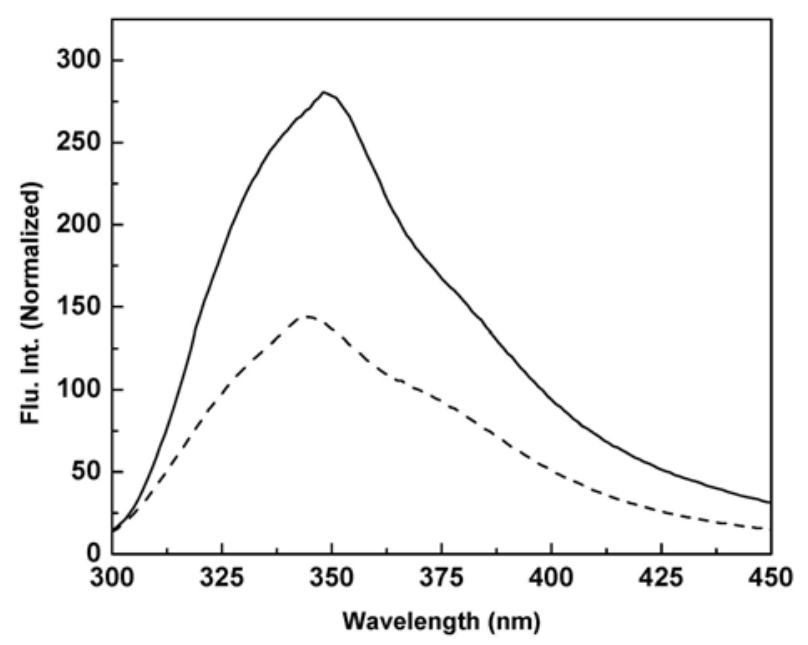

B

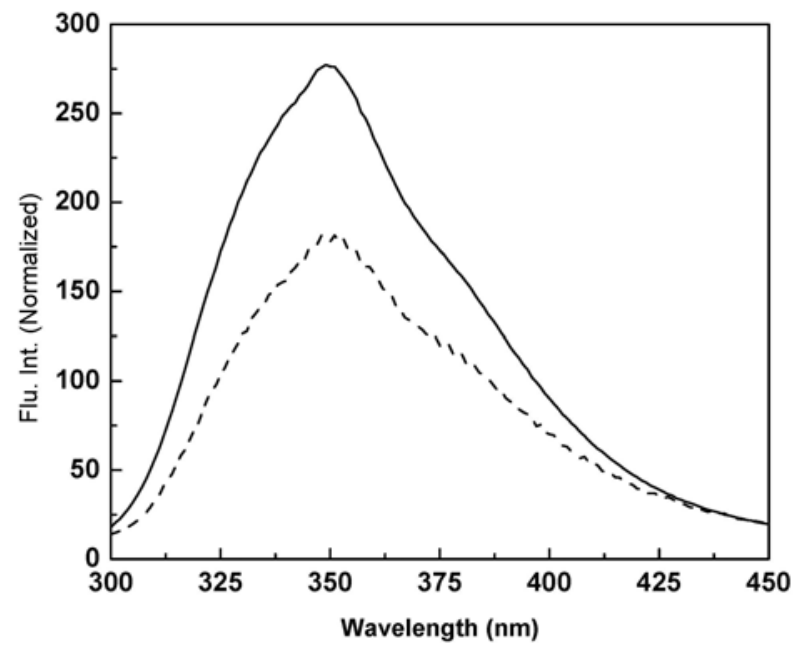

Figure S4. Steady-state Trp fluorescence of the SWNT binding peptides in the absence (solid lines) or in the presence of SWNT (dash lines). (A). UW-1 peptide. (B). B3 peptide. 
In order to define the $\beta$-turn-like structure of UW-1 peptide observed by CD experiments (Figure 2A), we employed a FRET strategy to measure the distance between its $\mathrm{N}$-terminus and residue 11 (i.e. Trp11). Because the Förster radius $\left(R_{0}\right)$ for the Trp-Sapphire 365 pair is not available, we experimentally determined the $R_{0}$ value based on the structurally well-studied protein of Staphylococcal nuclease (SNase), which contained a 6xHis-tag attached at its N-terminus. The distance representing the Trp-Sapphire 365 pair can be measured between Leu7 and Trp140 of SNase as the first six N-terminal residues are so flexible that they are not observed in X-ray crystallography. As examined from its PDB data (PDB 1SNC), the value is approximately $31.2 \AA$. The FRET efficiency is 0.32 measured from the spectra shown in Figure S5. Thus, the $R_{0}$ value of the Trp-Sapphire 365 pair is approximately $27.5 \AA$ using Eq. 2. 


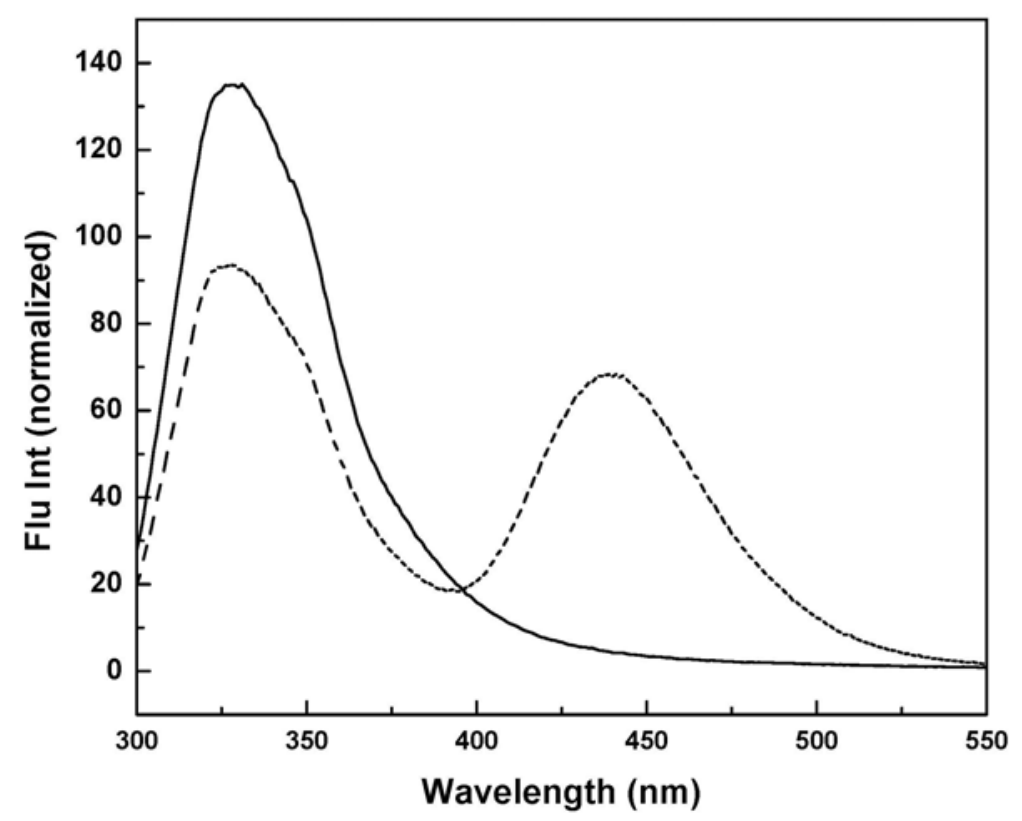

Figure S5. The fluorescence emission spectra of His6-SNase in the absence of Pro-Q Sapphire 365 (solid line) and in the presence of Pro-Q Sapphire 365 (dash line). Substantial fluorescence energy transfer occurs, as indicated by the large emission intensity from Pro-Q Sapphire 365 in the vicinity of $450 \mathrm{~nm}$ on excitation of the tryptophan at $289 \mathrm{~nm}$.

\section{Heteronuclear NMR}

The ${ }^{1} \mathrm{H}-{ }^{15} \mathrm{~N}$ HSQC spectrum of UW-1 peptide shows a narrow dispersion of the ${ }^{1} \mathrm{H}-{ }^{15} \mathrm{~N}$ correlation peaks (Figure S6), indicative of an unfolded conformation. Furthermore, no long-range NOEs were identified from NOSEY experiments (data not shown). These results are consistent with the observations from CD measurements. Currently, it is difficult to carry out solution NMR measurements of the UW-1 peptide in complex with SWNTs. Additional solid-state NMR investigations of the interaction 
of these peptides with SWNTs at the atomic resolution are currently in progress and will be reported elsewhere.

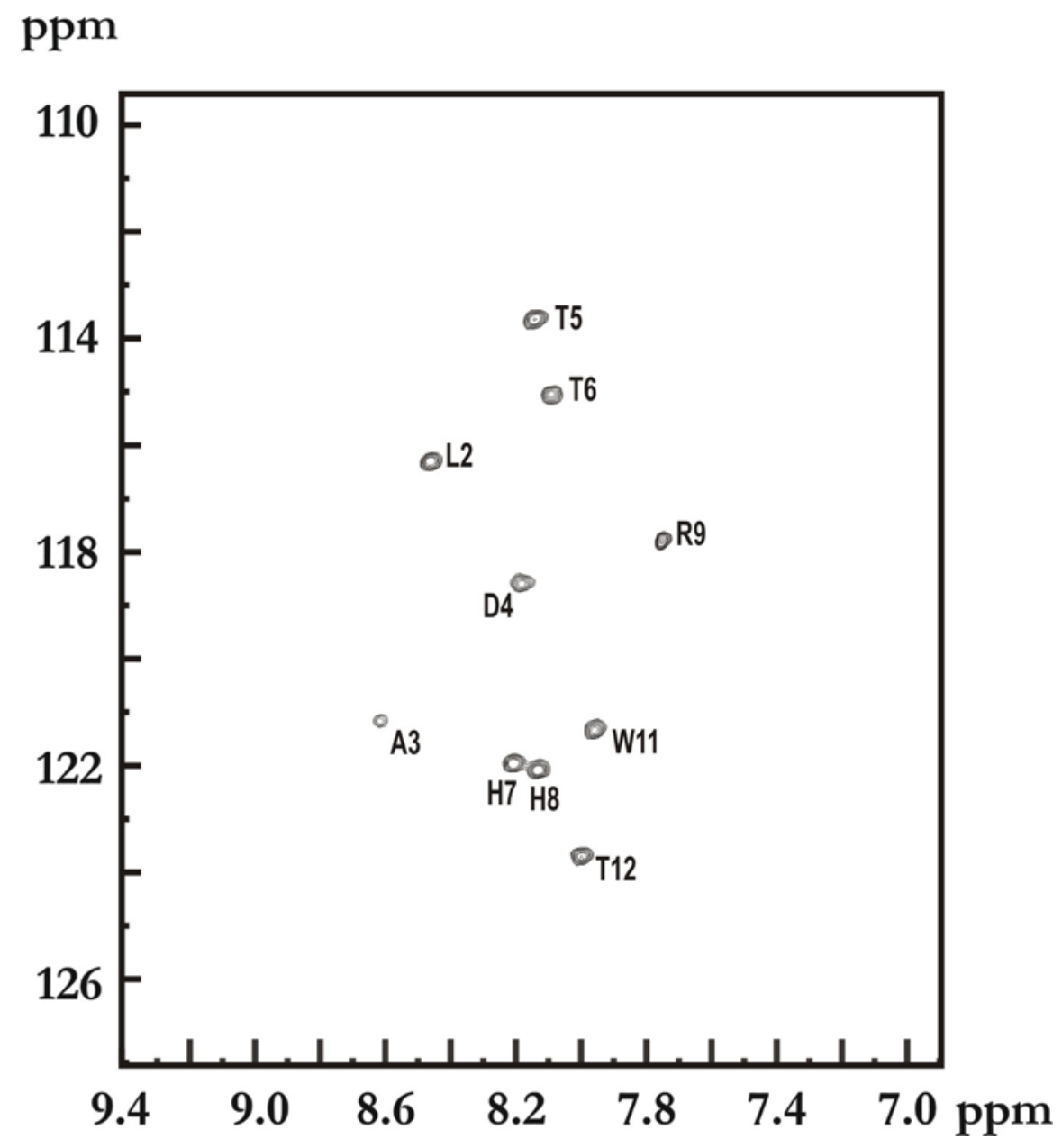

Figure S6. ${ }^{1} \mathrm{H}^{-15} \mathrm{~N}$ HSQC NMR spectrum of ${ }^{15} \mathrm{~N}$-labled recombinant UW-1 peptide. 


\section{References}

(1) Kase, D.; Kulp, J. L., III; Yudasaka, M.; Evans, J. S.; Iijima, S.; Shiba, K. Langmuir 2004, 20, 8939-8941.

(2) Wang, S.; Humphreys, E. S.; Chung, S. Y.; Delduco, D. F.; Lustig, S. R.; Wang, H.; Parker, K. N.; Rizzo, N. W.; Subramoney, S.; Chiang, Y. M.; Jagota, A. Nat.Mater. 2003, 2, 196-200.

(3) Inoue, H.; Nojima, H.; Okayama, H. Gene 1990, 96, 23-28.

(4) Gill, S. C.; von Hippel, P. H. Anal.Biochem. 1989, 182, 319-326.

(5) Su, Z.; Vinogradova, A.; Koutychenko, A.; Tolkatchev, D.; Ni, F. Protein Eng.Des.Sel. 2004, 17, 647-657.

(6) Osborne, M. J.; Su, Z.; Sridaran, V.; Ni, F. J Biomol.NMR 2003, 26, 317-326.

(7) Mori, S.; Abeygunawardana, C.; Johnson, M. O.; Vanzijl, P. C. M. Journal of Magnetic Resonance, Series B 1995, 108, 94-98.

(8) Johnson, B. A.; Blevins, R. A. Journal of Biomolecular NMR 1994, 4, 603-614.

(9) Dejoux, A.; Cieplax, P.; Hannick, N.; Moyna, G.; Dupradeau, F. Y. J Mol Model 2001, 7, 422-432.

(10) Permyakov, E. A. Luminescent Spectroscopy of Proteins; CRC Press, Boca Raton, FL. 1993. 